\title{
REVIEW
}

\section{Therapeutic inhibition of tumour necrosis factor $\alpha$ in patients with heart failure: cooling an inflamed heart}

\author{
P A Henriksen, D E Newby
}

Heart 2003;89:14-18

Heart failure is a systemic disorder characterised by tissue hypoxia and secondary organ dysfunction which occurs in response to various myocardial insults that include ischaemia, viral infections, and toxins. In addition to maladaptive neurohumoral activation, heart failure is associated with an inflammatory state that appears to have a detrimental effect on cardiac function and prognosis. This has led to the suggestion that anti-inflammatory interventions may have therapeutic potential in the symptomatic and prognostic treatment of patients with heart failure. This review considers the role of inhibition of the cytokine tumour necrosis factor $\alpha$ in the treatment of heart failure.
See end of article for authors' affiliations

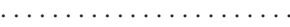

Correspondence to: Dr Peter Henriksen, Department of Cardiology, Royal Infirmary, Lauriston

Place, Edinburgh EH3 9YW, UK;

p.henriksen@ed.ac.uk

Accepted 2 October 2002
$\mathrm{T}$ umour necrosis factor $\alpha(\mathrm{TNF} \alpha)$ is a 157 amino acid cytokine that is produced in response to inflammatory or infectious stimuli by macrophages, lymphocytes, neutrophils, and structural cells including fibroblasts and smooth muscle cells. It is one of many immunological mediators involved in critical aspects of cell function including the response to injury, inflammation, and death through necrosis or apoptosis. We describe the rationale for, and results of, recent clinical trials of TNF $\alpha$ blockade in patients with chronic heart failure.

\section{TUMOUR NECROSIS FACTOR $\alpha$ : A PROINFLAMMATORY PLEIOTROPIC CYTOKINE}

TNF $\alpha$ acts through two transmembrane receptors, TNF $\alpha$ receptor (TNFR) types 1 and 2 . When stimulated, these receptors interact with a variety of cell signal pathways increasing expression of proinflammatory cytokines, such as interleukin 6, and regulating cell survival, growth, and apoptotic death. However, the response to TNF $\alpha$ is

Table 1 Contrasting actions of tumour necrosis factor $\alpha$ in patients with heart failure

\begin{tabular}{ll}
\hline Adaptive & Maladaptive \\
\hline Myocardial hibernation & Reduced myocyte contractility \\
Inhibition of apoptosis & Apoptosis \\
Hypertrophy & Fibrosis \\
& Leucocyte recruitment \\
& Impaired vascular function \\
& Induction of inflammation \\
\hline
\end{tabular}

non-uniform and critically depends upon the cell type, the state of cellular activation, and the local concentrations of the cytokine (table 1). For example, TNF $\alpha$ may promote cell survival and proinflammatory gene expression, and yet in the presence of transcription factor blockade the same stimulus may drive the cell towards apoptosis and death. This contextual dependence of $\mathrm{TNF} \alpha$ action is not only restricted to in vitro observations. Infusion of TNF $\alpha$ in healthy humans produces vasoconstriction ${ }^{1}$ and procoagulant effects, ${ }^{2}$ while in volunteers injected with endotoxin, high TNF $\alpha$ concentrations are associated with hypotension, increased vascular permeability, and myocardial depression. ${ }^{3}$ Thus the environment within which the TNF $\alpha$ signal is received is crucial and may explain some of the conflicting evidence regarding its actions on cardiomyocyte function and survival.

\section{TUMOUR NECROSIS FACTOR $\alpha$ AND HEART FAILURE}

Cytokines have been implicated in the syndrome of chronic heart failure for over a decade. ${ }^{4}$ Levine and colleagues $^{5}$ first described raised plasma TNF $\alpha$ concentrations in non-septic patients with chronic heart failure. Subsequent studies showed comparable elevations of two other cytokines, interleukin 6 and interleukin $1 \beta$ (IL-1 $\beta$ ), ${ }^{6}$ and a direct correlation between plasma TNF $\alpha$ concentrations and the degree of heart failure, as assessed by functional heart failure classification ${ }^{7}$ (fig 1). The increase in plasma TNF $\alpha$ concentrations appears to be most striking in those patients with generalised body wasting or cardiac cachexia-a clinical feature that is particularly associated with a poor prognosis. ${ }^{89}$ However, plasma TNF $\alpha$ concentrations are not necessarily representative of the functional activity of the cytokine. Localised myocardial production of TNF $\alpha$ has been demonstrated within the failing heart, suggesting that there may be significant additional autocrine or paracrine actions. ${ }^{10}$

\section{What drives TNF $\alpha$ production in patients} with heart failure?

Inflammation contributes to the development and progression of heart failure, ${ }^{11}$ and markers of

Abbreviations: ATTACH, anti-TNF alpha therapy against chronic heart failure; IL-1 $\beta$, interleukin $1 \beta$; iNOS, inducible nitric oxide synthase; NF- $\kappa B$, nuclear factor $\kappa B$; RENAISSANCE, ramdomized etanercept North American strategy to study antagonism of cytokines; RECOVER, research into etanercept antagonism in ventricular dysfunction; TNF $\alpha$, tumour necrosis factor $\alpha$; TNFR, tumour necrosis factor $\alpha$ receptor 


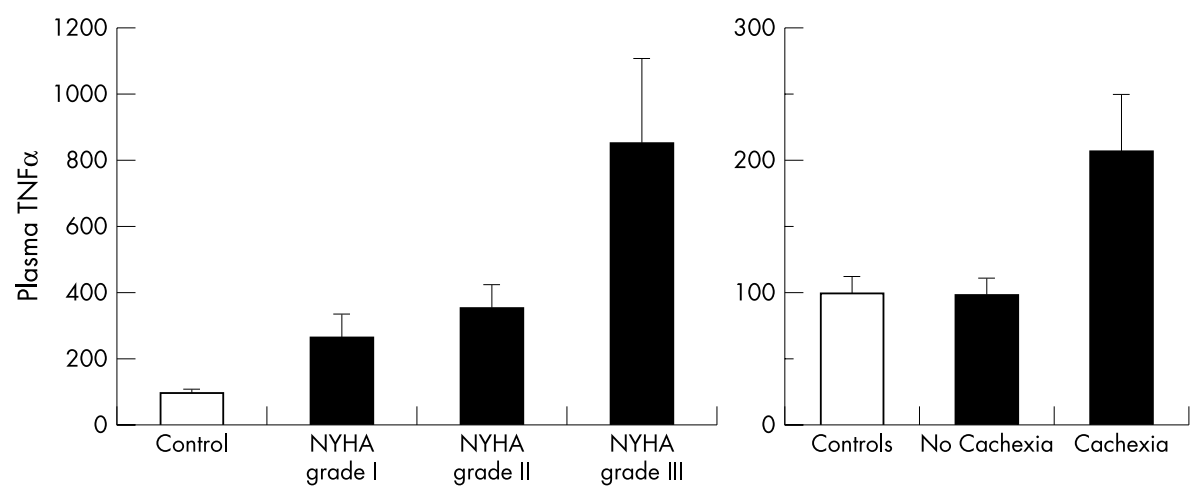

Figure 1 Relative (percentage) plasma tumour necrosis factor $\alpha$ concentrations according to New York Heart Association (NYHA) classification of symptoms (left panel; data from Torre-Amione and colleagues ${ }^{10}$ ) and the presence of cachexia (right panel; data from Anker and colleagues 9 ) in patients with heart failure.

inflammation, such as $\mathrm{C}$ reactive protein, are independent predictors of the presence of heart failure. ${ }^{12}$ TNF $\alpha$ production represents a phylogenetically conserved response to cellular stress, inflammation, and injury. The specific stimuli responsible for increased TNF $\alpha$ production in patients with heart failure have not been elucidated but there are several potential candidates.

Endotoxin, a component of the outer coat of Gram negative bacteria, is a potent stimulus for macrophage TNF $\alpha$ production and it is intriguing that non-septic patients with decompensated failure and oedema are more likely to have subclinical endotoxaemia. ${ }^{13}$ Indeed, resolution of oedema with diuretic treatment is associated with the disappearance of endotoxin, leading to a proposal that oedematous bowel is more permeable to bacteria.

Plasma markers of oxidative stress are increased in patients with heart failure. ${ }^{14}{ }^{15}$ The tissue origins of these markers have not been elucidated, although poorly perfused peripheral muscles and the failing myocardium are likely candidates. $\mathrm{TNF} \alpha$ and angiotensin II stimulate free radical production in a variety of cell types ${ }^{16}$ and contribute to oxidative stress in patients with heart failure. The reactive oxygen species produced may exert their effect through the nuclear factor $\mathrm{\kappa B}$ (NF- $\mathrm{KB}$ ) system, a ubiquitous transcription factor responsive to oxidative stress. ${ }^{17}$ Active NF- $\mathrm{KB}$ is present within failing cardiomyocytes, and its activity correlates inversely with the improvement associated with a left ventricular assist device. ${ }^{18}$ It interacts with the regulatory elements of many genes concerned with response to injury, including TNF $\alpha$ itself and inducible nitric oxide synthase (iNOS). The NF- $\mathrm{KB}$ transcription factor system may be one point of molecular convergence for diverse pathologies-including ischaemia, haemodynamic overload, ${ }^{19}$ and viral infection-that result in increased TNF $\alpha$ expression in patients with cardiac failure.

\section{ADVERSE CARDIAC EFFECTS OF TNF $\alpha$ Myocyte contractility}

TNF $\alpha$ impairs myocyte contractility. It has been shown to have negative inotropic activity measured both by left ventricular pressure-volume curves and isolated cardiac myocyte fractional shortening. ${ }^{20}$ This results from a decrease in the voltage dependent calcium current responsible for depolarisation of the myocyte and the release of sarcoplasmic reticular calcium stores. Although uncoupling of $\beta$ adrenoceptors from their intracellular signalling pathways may have a role, ${ }^{21}$ this effect appears to be mediated, at least in part, through mechanisms that involve increased nitric oxide synthesis.

Nitric oxide has negative inotropic effects that include the inhibition of creatine kinase ${ }^{22}$ and the downregulation of mitochondrial respiration. ${ }^{23}$ TNF $\alpha$ increases the expression and synthesis of iNOS that has been described in the myocardium of patients with heart failure. ${ }^{24}{ }^{25}$ Nitric oxide synthase inhibition is able to reverse the TNF $\alpha$ mediated reductions in isolated ventricular papillary muscle tension. ${ }^{26}$ However, these findings are not universal, and Mann's group failed to demonstrate reversal of myocardial depression with a nitric oxide synthase inhibitor following TNF $\alpha$ infusions in rats. ${ }^{27}$

\section{Myocardial fibrosis and apoptosis}

Transgenic mice which selectively overexpress TNF $\alpha$ in cardiomyocytes have a phenotype of myocarditis with interstitial infiltrates, four chamber dilatation, and compensatory myocyte hypertrophy. ${ }^{28}$ There are striking parallels between these transgenic murine $\mathrm{TNF} \alpha$ hearts and the myocardium of patients with chronic heart failure. At the cellular level, transgenic hearts have patterns of gene expression that are particular to failing myocardium. These include reactivation of the fetal gene programme within the ventricle (for example, atrial natriuretic factor) and an increase in metalloprotease activity that facilitates extracellular matrix remodelling. Interstitial cell (and to a lesser extent myocyte) apoptosis is also a consistent feature of the transgenic myocardium. ${ }^{29}$

The transgenic models may represent one extreme of sustained or excessive production of TNF $\alpha$. The generation of $\mathrm{TNF} \alpha$ is initially compensatory and sufficient to promote the hypertrophic growth of cardiac myocytes and to induce the expression of cytoprotective antiapoptotic factors in a variety of cell types. ${ }^{30}$ This protective role is borne out by the observation that TNFR-1/TNFR-2 deficient mice have an increased susceptibility to cardiomyocyte apoptosis following myocardial infarction. ${ }^{31}$ These studies illustrate the potentially important and contrasting roles of TNF $\alpha$ as a negative inotrope following prolonged expression in the failing myocardium, while paradoxically acting as a protective agent limiting myocyte death during acute ischaemia and infarction.

\section{THERAPEUTIC INHIBITION OF TNF $\alpha$ IN PATIENTS WITH HEART FAILURE \\ Rationale}

If cytokine production represents a maladaptive response to cellular injury leading to further organ dysfunction (compare the neurohormonal activation occurring in heart failure), then inhibition of TNF $\alpha$ may be beneficial. Several lines of evidence suggest this may be the case.

\section{Animal models}

Anti-TNF $\alpha$ treatments were first assessed in animal models of septicaemia. Infusion of recombinant TNFR-2 fragments protected rabbits from bacterial endotoxin induced septic shock. This was associated with an improvement in cardiac output and arterial pressure, indicating that TNF $\alpha$ blockade was effective in reversing the depressed myocardial contractility and vascular tone associated with this condition. ${ }^{32}$ Subsequent studies in the TNF $\alpha$ transgenic mouse have shown that neutralising fragments of the TNF $\alpha$ receptor attenuate certain features of the heart failure phenotype. Interstitial infiltrates were reduced and matrix metalloprotease concentrations returned to normal, although hypertrophy and fibrosis 
persisted. ${ }^{33}$ Both these septic and transgenic animal models are characterised by myocardial depression in the context of extreme TNF $\alpha$ production. Little work has been done on TNF $\alpha$ blockade in heart failure models more relevant to human disease, although one group has shown an improvement in cardiac function following ischaemia-reperfusion injury in rabbit hearts treated with neutralising TNF $\alpha$ antibody. ${ }^{34}$

\section{Clinical observational studies}

A progressive increase in plasma TNF $\alpha$ with increasing severity of decompensated heart failure and a fall with therapeutic intervention provides indirect evidence that strategies to reduce TNF $\alpha$ signalling may be beneficial. Two further observations lend support to this view. High intracellular concentrations of adenosine would be expected to reduce TNF $\alpha$ production, and a mutation in the adenosine monophosphate deaminase-1 gene, which slows adenosine metabolism, is associated with improved survival following symptom onset in patients with heart failure. ${ }^{35}$ Second, phosphodiesterase inhibitors can also serve as inhibitors of TNF $\alpha$ production, and the phosphodiesterase inhibitor pentoxyfilline significantly improved symptoms and left ventricular ejection fraction in patients with idiopathic dilated cardiomyopathy over a period of six months. ${ }^{36}$ However, there are several potential alternative explanations for these clinical observations and it is unclear whether any of these effects are mediated through TNF $\alpha$. Moreover, all previous clinical experience with the prolonged use of phosphodiesterase inhibitors, such as milrinone, suggests that their positive inotropic activity worsens long term survival.

\section{Therapeutic agents}

The favourable results of anticytokine treatment in other inflammatory diseases ${ }^{37}$ have paved the way for trials of TNF $\alpha$ blockade in patients with heart failure. Two antagonists that bind and neutralise circulating $\mathrm{TNF} \alpha$ are currently licensed and have been successfully used in the treatment of rheumatoid arthritis and inflammatory bowel disease. Etanercept is a fusion protein that employs a TNFR-2 fragment to recognise circulating TNF $\alpha$. It is effective in reducing markers of acute inflammation, improving functional scores, and, importantly, slowing progression of joint damage in patients with severe rheumatoid arthritis in comparison with methotrexate. ${ }^{38}$ The treatment remains effective and well tolerated during long term administration and follow up.

Another strategy to inhibit cytokine signalling is the use of neutralising monoclonal antibodies, although potential drawbacks include direct activation of the complement system leading to cell lysis and loss of efficacy with the development of host antibodies. Analogous to abciximab, infliximab is a monoclonal antibody that has been raised in mice with neutralising activity against human TNF $\alpha$. In order to reduce the immunogenicity of this mouse protein, a chimeric construct has been produced with segments of the protein replaced with human counterparts. This treatment has proven efficacy in patients with rheumatoid arthritis ${ }^{39}$ and inflammatory bowel disease, ${ }^{37}$ and early clinical trials suggest it may have a therapeutic role in patients with severe psoriasis. ${ }^{40}$

As the use of etanercept and infliximab has increased, so have reports of undesirable side effects relating to immunosuppression, including invasive pulmonary aspergillosis, ${ }^{41}$ aseptic meningitis, ${ }^{42}$ and in particular the reactivation of tuberculosis with infliximab. Patients should be screened for latent tuberculosis infection before receiving infliximab, and the occurrence of rare but serious side effects relating to immunosuppression may limit the widespread applicability of both these treatments to heart failure populations.

\section{Early clinical experience in heart failure}

Early trials of TNF $\alpha$ blockade in patients with heart failure were encouraging. A pilot double blind randomised controlled trial of etanercept, given as a single intravenous infusion, led to significant increases in quality of life scores, six minute walk distance, and ejection fraction in 18 patients with moderately severe heart failure. ${ }^{43}$ Positive effects were only seen in higher dose groups and a follow up study examined the effects of prolonged antagonism with twice weekly subcutaneous doses given for three months. The treatment was well tolerated and again significant dose dependent improvements in functional status and ventricular function were reported, although the numbers were small $(\mathrm{n}=47) \cdot{ }^{44}$ Etanercept also appears to correct the impaired endothelium dependent vasodilatation in patients with heart failure, an effect that was proportional to the plasma TNF $\alpha$ concentrations. ${ }^{45}$ However, this initial promise was not borne out by two larger trials (RECOVER and RENAISSANCE) that randomised over 1500 patients with NYHA grade II-IV heart failure in Europe and North America, respectively. Last year, both trials were stopped early because of the apparent futility of the treatment on an interim analysis, with little likelihood of any benefit in terms of symptoms, hospital admissions, or deaths. The complete findings of these studies have yet to be published (table 2).

There has been only one small scale phase II trial of infliximab in patients with heart failure. The ATTACH trial recruited 150 patients with NYHA grade III-IV heart failure who were randomised to placebo, low dose infliximab, and high dose infliximab. This trial was also terminated early owing to an apparent excess of hospital admissions and deaths, particularly in patients receiving the higher dose.

Table 2 Recent trials of anti-tumour necrosis factor $\alpha$ treatment in patients with heart failure

\begin{tabular}{|c|c|c|c|}
\hline Trial & Design & Outcome & Published \\
\hline Deswal et al & $\begin{array}{l}\text { Randomised double blind multidose pilot study of } \\
\text { etanercept in } 18 \text { patients with NYHA III heart failure }\end{array}$ & $\begin{array}{l}\text { Etanercept was well tolerated and higher doses were } \\
\text { associated with significant improvements in quality of } \\
\text { life scores, } 6 \text { minute walk test, and left ventricular } \\
\text { ejection fraction }\end{array}$ & Yes $^{43}$ \\
\hline Bozkurt et al & $\begin{array}{l}\text { Randomised double blind multidose pilot study of } \\
\text { etanercept in } 47 \text { patients with NYHA III-IV heart } \\
\text { failure }\end{array}$ & $\begin{array}{l}\text { Etanercept was well tolerated with a significant } \\
\text { improvement in echocardiographic measures of left } \\
\text { ventricular function and a weak non-significant } \\
(\mathrm{p}=0.20) \text { trend towards improvement in the combined } \\
\text { clinical end point }\end{array}$ & Yes $^{44}$ \\
\hline RENAISSANCE and RECOVER & $\begin{array}{l}\text { North American and European limbs of a randomised } \\
\text { controlled trial examining two dosage regimes of } \\
\text { etanercept in } 1500 \text { patients with NYHA II-IV heart } \\
\text { failure and an ejection fraction }<30 \%\end{array}$ & $\begin{array}{l}\text { Terminated early owing to futility, with no likelihood } \\
\text { of treatment benefit in the primary composite end } \\
\text { point of NYHA class, patient global assessment, } \\
\text { hospital admission, and death }\end{array}$ & No \\
\hline ATTACH & $\begin{array}{l}\text { A pilot randomised controlled trial evaluating } \\
\text { infliximab in } 150 \text { patients with stable NYHA III-IV } \\
\text { heart failure, ejection fraction }<35 \% \text {, and no } \\
\text { concurrent infections }\end{array}$ & $\begin{array}{l}\text { No difference in clinical status at } 14 \text { weeks with no } \\
\text { benefit at } 28 \text { weeks; a trend towards worsening } \\
\text { clinical status in the treatment group }\end{array}$ & No \\
\hline
\end{tabular}

NYHA, New York Heart Association classification of heart failure. 


\section{FUTURE PERSPECTIVES}

The evidence implicating TNF $\alpha$ and other cytokines in the pathogenesis of heart failure is compelling. Clinical trials may have been considered premature, given that the mechanisms through which TNF $\alpha$ blockade could be beneficial are unknown. The potential adverse effects of this novel treatment are of concern, and the cytoprotective properties of TNF $\alpha$ may be more important to certain categories of patients with heart failure who may deteriorate following TNF $\alpha$ blockade. The cost of long term administration and the possibility of side effects from immunosuppression and hypersensitivity to these agents are further problems that need to be addressed.

Clinical trials of TNF $\alpha$ blockade have failed to produce the expected benefits in a large non-selective population of patients with stable heart failure. Selected patient populations with certain TNF $\alpha$ promoter polymorphisms may be predisposed to TNF $\alpha$ induced ventricular dysfunction. Future anti-TNF $\alpha$ trials may be able to target patients with susceptible genotypes, and a recent study demonstrated overrepresentation of the TNF $\alpha 2$ allele-a promoter polymorphism associated with increased inducible transcription of TNF $\alpha$-in patients with non-ischaemic left ventricular dysfunction. ${ }^{46}$

Generation of inflammatory mediators is a secondary event in most cases of heart failure, and the balance of maladaptive versus adaptive effects may change following disease progression or during acute exacerbations. It may be that differences in the aetiology of heart failure are important, and future research should focus on dissecting out the critical pathways mediating ventricular dysfunction and determining which patients may benefit most. It should also be remembered that the inflammatory response to heart failure is associated with the release of many cytokines and not just TNF $\alpha$. For example, IL- $1 \beta$ is a cytokine with similar signalling properties to TNF $\alpha$, is produced by cardiomyocytes, and is also increased in heart failure. The deleterious actions of IL- $1 \beta$ will not be ameliorated by anti-TNF $\alpha$ treatment and this may contribute to treatment failure. ${ }^{47}$ Alternative anti-inflammatory or anticytokine treatments, used alone or in combination, now need to be explored.

\section{ACKNOWLEDGEMENTS}

PAH is supported by a Wellcome Trust clinical training fellowship at the University of Edinburgh. DEN is conducting work in this area supported by the British Heart Foundation (PG/2001/068).

\section{Authors' affiliations}

P A Henriksen, D E Newby, Department of Cardiology, University of Edinburgh, Royal Infirmary, Lauriston Place, Edinburgh, UK

\section{REFERENCES}

1 Nakamura M, Yoshida H, Arakawa N, et al. Effects of tumor necrosis factor-alpha on basal and stimulated endothelium-dependent vasomotion in human resistance vessel. J Cardiovasc Pharmacol 2000;36:487-92.

2 van der Poll T, Buller HR, ten Cate $\mathrm{H}$, et al. Activation of coagulation after administration of tumor necrosis factor to normal subjects. N Engl J Med 1990;322:1622-7.

3 Suffredini AF, Fromm RE, Parker MM, et al. The cardiovascular response of normal humans to the administration of endotoxin. N Engl J Med 1989:321:280-7.

4 Adamopoulos S, Parissis JT, Kremastinos DT. A glossary of circulating cytokines in chronic heart failure. Eur J Heart Fail 2001 ; 3:517-26.

5 Levine B, Kalman J, Mayer L, et al. Elevated circulating levels of tumor necrosis factor in severe chronic heart failure. N Engl J Med 1990;323:236-41.

6 Testa $M$, Yeh M, Lee $P$, et al. Circulating levels of cytokines and their endogenous modulators in patients with mild to severe congestive heart failure due to coronary artery disease or hypertension. J Am Coll Cardiol 1996;28:964-71.

7 Torre-Amione G, Kapadia S, Benedict C, et al. Proinflammatory cytokine levels in patients with depressed left ventricular ejection fraction a report from the Studies of Left Ventricular Dysfunction (SOLVD). J Am Coll Cardiol 1996;27:1201-6.

8 McMurray J, Abdullah I, Dargie HJ, et al. Increased concentrations of tumour necrosis factor in "cachectic" patients with severe chronic heart failure. Br Heart J 1991;66:356-8.
9 Anker SD, Ponikowski PP, Clark AL, et al. Cytokines and neurohormones relating to body composition alterations in the wasting syndrome of chronic heart failure. Eur Heart J 1999;20:683-93.

10 Torre-Amione G, Kapadia S, Lee J, et al. Expression and functional significance of tumor necrosis factor receptors in human myocardium. Circulation 1995; 92:1487-93.

11 Young JB. Heart failure is a fever: the cytokine connection. Cleve Clin J Med 2000;67:801-3

12 Gottdiener JS, Arnold AM, Aurigemma GP, et al. Predictors of congestive heart failure in the elderly: the Cardiovascular Health Study. J Am Coll Cardiol 2000;35: 1628-37.

13 Niebauer J, Volk HD, Kemp M, et al. Endotoxin and immune activation in chronic heart failure: a prospective cohort study. Lancet 1999;353:1838-42.

14 McMurray J, Chopra M, Abdullah I, et al. Evidence of oxidative stress in chronic heart failure in humans. Eur Heart J 1993;14:1493-8.

15 Keith M, Geranmayegan A, Sole M, et al. Increased oxidative stress in patients with congestive heart failure. J Am Coll Cardiol 1998;31:1352-6.

16 Griendling KK, Minieri CA, Ollerenshaw JD, et al. Angiotensin II stimulates NADH and NADPH oxidase activity in cultured vascula smooth muscle cells. Circ Res 1994;74:1141-8.

17 Barnes PJ, Karin M. Nuclear factor-kappaB: a pivotal transcription factor in chronic inflammatory diseases. N Engl J Med 1997;336:1066-71.

18 Grabellus F, Levkau B, Sokoll A, et al. Reversible activation of nuclear factor-kappaB in human end-stage heart failure after left ventricular mechanical support. Cardiovasc Res 2002;53:124-30.

19 Liang F, Gardner DG. Mechanical strain activates BNP gene transcription through a p38/NF- kappaB dependent mechanism. J Clin Invest 1999:104:1603-12.

20 Yokoyama T, Vaca L, Rossen RD, et al. Cellular basis for the negative inotropic effects of tumor necrosis factor-alpha in the adult mammalian heart. J Clin Invest 1993;92:2303-12.

21 Gulick T, Chung MK, Pieper SJ, et al. Interleukin 1 and tumor necrosis factor inhibit cardiac myocyte beta-adrenergic responsiveness. Proc Nat Acad Sci USA 1989:86:6753-7.

22 Gross WL, Bak MI, Ingwall JS, et al. Nitric oxide inhibits creatine kinase and regulates rat heart contractile reserve. Proc Natl Acad Sci USA 1996;93:5604-9

23 Lizasoain I, Moro MA, Knowles RG, et al. Nitric oxide and peroxynitrite exert distinct effects on mitochondrial respiration which are differentially blocked by glutathione or glucose. Biochem J 1996;314:877-80.

24 Habib FM, Springall DR, Davies GJ, et al. Tumour necrosis factor and inducible nitric oxide synthase in dilated cardiomyopathy. Lancet 1996:347:1151-5.

25 de Belder AJ, Radomski MW, Why HJ, et al. Nitric oxide synthase activities in human myocardium. Lancet 1993;341:84-5.

26 Finkel MS, Oddis CV, Jacob TD, et al. Negative inotropic effects of cytokines on the heart mediated by nitric oxide. Science 1992;257:387-9.

27 Bozkurt B, Kribbs SB, Clubb FJ, et al. Pathophysiologically relevant concentrations of tumor necrosis factor-alpha promote progressive left ventricular dysfunction and remodeling in rats. Circulation 1998:97:1382-91.

28 Bryant D, Becker L, Richardson J, et al. Cardiac failure in transgenic mice with myocardial expression of tumor necrosis factor-alpha. Circulation 1998;97:1375-81.

29 Kubota T, McTiernan CF, Frye CS, et al. Dilated cardiomyopathy in transgenic mice with cardiac-specific overexpression of tumor necrosis factor-alpha. Circ Res 1997;81:627-35.

30 Melino G, Bernassola F, Knight RA, et al. S-nitrosylation regulates apoptosis. Nature 1997;388:432-3.

31 Kurrelmeyer KM, Michael LH, Baumgarten G, et al. Endogenous tumo necrosis factor protects the adult cardiac myocyte against ischemic-induced apoptosis in a murine model of acute myocardial infarction. Proc Natl Acad Sci USA 2000;97:5456-61.

32 Porat R, Paddock HN, Schwaitzberg SD, et al. Glycosylated recombinant human tumor necrosis factor binding protein-1 reduces mortality, shock, and production of tumor necrosis factor in rabbit Escherichia coli sepsis. Crit Care Med 1995:23:1080-9.

33 Kubota T, Bounoutas GS, Miyagishima M, et al. Soluble tumor necrosis factor receptor abrogates myocardial inflammation but not hypertrophy in cytokine-induced cardiomyopathy. Circulation 2000;101:2518-25.

34 Stamm C, Friehs I, Cowan DB, et al. Inhibition of tumor necrosis factor-alpha improves postischemic recovery of hypertrophied hearts. Circulation 2001; 104:1350-55.

35 Loh E, Rebbeck TR, Mahoney PD, et al. Common variant in AMPDI gene predicts improved clinical outcome in patients with heart failure. Circulation 1999;99:1422-5.

36 Skudicky D, Bergemann A, Sliwa K, et al. Beneficial effects of pentoxifylline in patients with idiopathic dilated cardiomyopathy treated with angiotensin-converting enzyme inhibitors and carvedilol: results of a randomized study. Circulation 2001;103:1083-8.

37 Blam ME, Stein RB, Lichtenstein GR. Integrating anti-tumor necrosis facto therapy in inflammatory bowel disease: current and future perspectives. Am J Gastroenterol 2001:96:1977-97.

38 Bathon JM, Martin RW, Fleischmann RM, et al. A comparison of etanercept and methotrexate in patients with early rheumatoid arthritis. N Engl J Med 2000;343: 1586-93.

39 Taylor PC. Anti-tumor necrosis factor therapies. Curr Opin Rheumatol 2001;13:164-9.

40 Chaudhari U, Romano P, Mulcahy LD, et al. Efficacy and safety of infliximab monotherapy for plaque-type psoriasis: a randomised trial. Lancet $2001 ; 357: 1842-7$. 
41 Warris A Bjorneklett A, Gaustad P. Invasive pulmonary aspergillosis associated with infliximab therapy. N Engl J Med 2001;344:1099-100. 42 Marotte H, Charrin JE, Miossec P. Infliximab-induced aseptic meningitis. Lancet 2001;358:1784.

43 Deswal A, Bozkurt B, Seta Y, et al. Safety and efficacy of a soluble P75 tumor necrosis factor receptor (Enbrel, etanercept) in patients with advanced heart failure. Circulation 1999;99:3224-6.

44 Bozkurt B, Torre-Amione G, Warren MS, et al. Results of targeted anti-tumor necrosis factor therapy with etanercept (Enbrel) in patients with advanced heart failure. Circulation 2001:103:1044-7.
45 Fichtlscherer S, Rossig L, Breuer S, et al. Tumor necrosis factor antagonism with etanercept improves systemic endothelial vasoreactivity in patients with advanced heart failure. Circulation $2001 ; 104: 3023-5$

46 Densem CG, Hutchinson IV, Yonan N, et al. Tumour necrosis factor alpha gene polymorphism: a predisposing factor to non-ischaemic myocardial dysfunction? Heart 2002;87:153-5.

47 Long CS. The role of interleukin-1 in the failing heart. Heart Fail Rev $2001 ; 6: 81-94$

\section{IMAGES IN CARDIOLOGY}

\section{A novel form of spontaneous coronary vasospasm: bead-like vasospasm in an elderly man}

A

3 year old man presented with anginal chest pain and dyspnoea at rest in the morning. Echocardiography showed moderate mitral regurgitation and normal left ventricular wall motion. Coronary angiography revealed spontaneous tandem vasospasm, which looked like beads, in the first diagonal branch of the left anterior descending artery, but no significant spastic or organic stenosis in other segments (panel A). An intracoronary injection of $0.5 \mathrm{mg}$ glyceryl trinitrate quickly relieved this bead-like vasospasm (panel B). An acetylcholine provocation test was carried out seven days later. All coronary vasodilating drugs were discontinued more than 24 hours before the examination. Repeated coronary angiography revealed no significant vasospasm in any coronary artery. Intracoronary injection of $50 \mu \mathrm{g}$ acetylcholine into the left coronary artery caused diffuse and
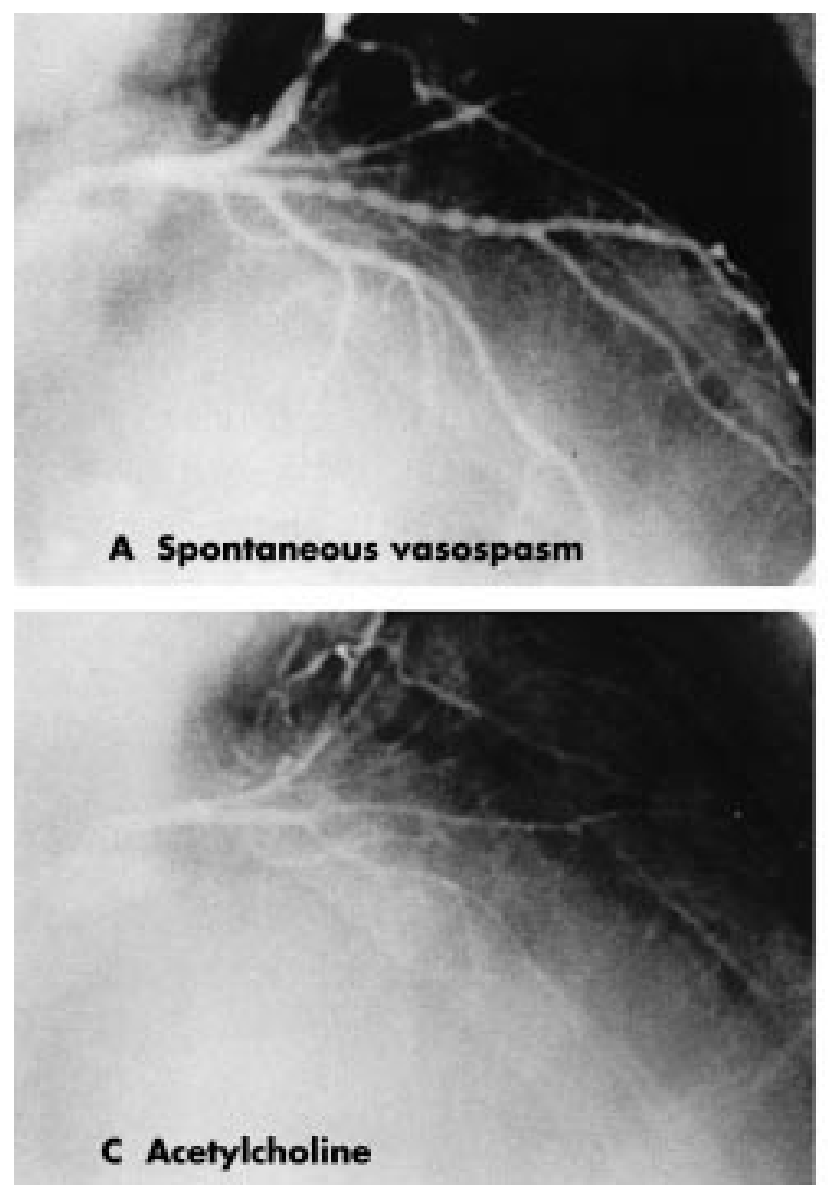

severe vasospasm in many segments, but could not reproduce the bead-like vasospasm (panel C). Again, an intracoronary injection of glyceryl trinitrate quickly relieved the vasospasm (panel D).

To the best of our knowledge, this is the first published report of a patient with bead-like vasospasm, and it suggests that the acetylcholine provocation test does not always reproduce the clinical vasospasm. How this mysterious form of vasospasm occurs remains unknown.
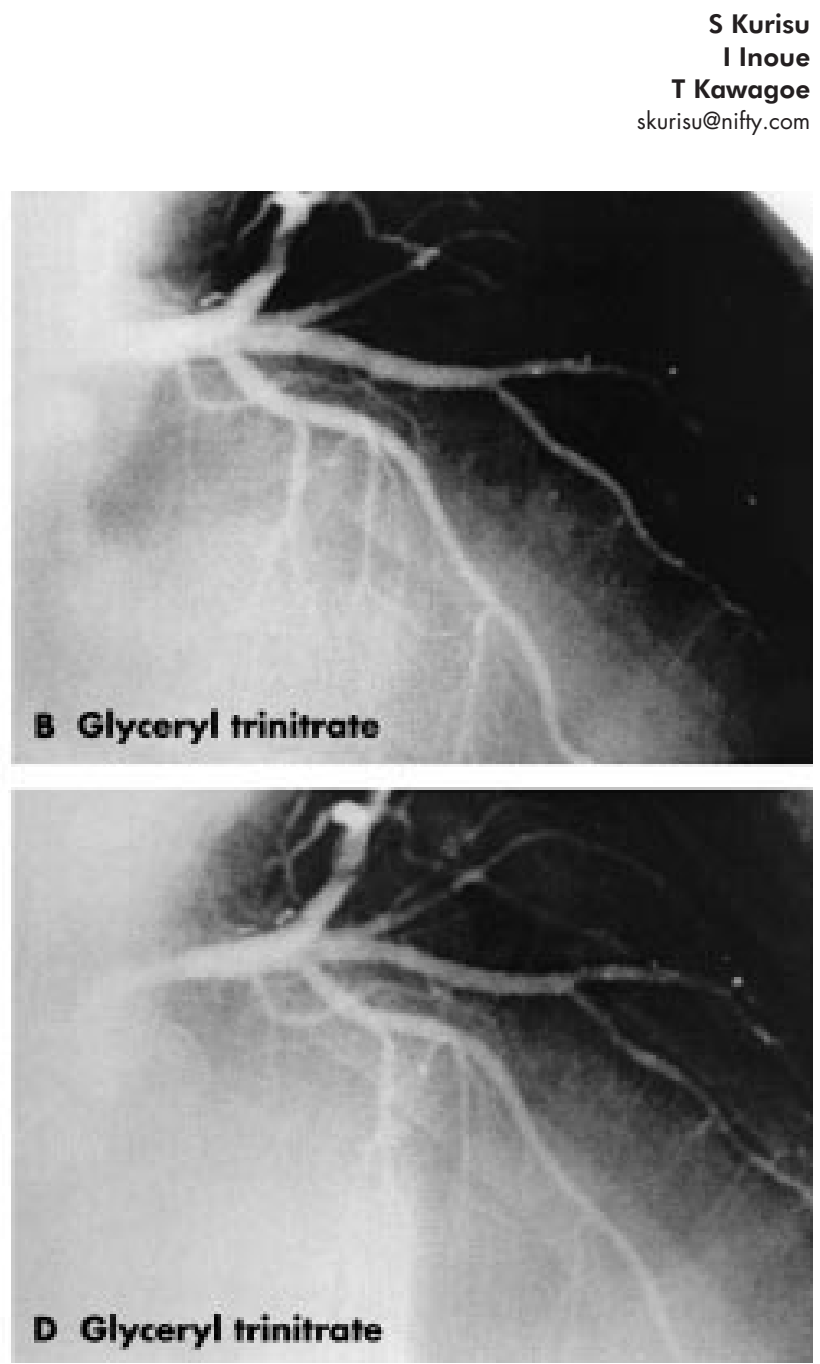